\title{
CORRESPONSALS ESTRANGERS DE JOAN BROSSA: COL·LABORACIONS I DIÀLEGS SOBRE ART I POESIA EXPERIMENTALS DES DE 1950 A $1998^{1}$
}

\author{
GLÒRIA BORDONS \& CARLOTA CAULFIELD
}

\begin{abstract}
The Brossa Collection documents the life and work of one of the twentieth century's most influential avant-garde Catalan poets. The collection includes 2,991 letters by and to Joan Brossa (1919-1998) from the mid-1950s to the late 1990s. Brossa was a prolific letter-writing poet and established dynamic relationships with artists, poets, performers, art critics, and translators from all around the world. Among them were João Cabral de Melo, Jacques Dupin, Alain Arias-Misson, Adriano Spatola, Felipe Boso, Roland Penrose, Julien Blaine, Sarenco, Klaus Peter Dencker, Julie Lawson, and John London. The correspondence reveals the extent of Brossa's network of contacts who supported his work and his life in numerous ways. With this essay we open up for the first time the treasure trove of never before published letters to Brossa. The letters are full of intellectual banter and have awe-inspiring visual materials.
\end{abstract}

"Écrire, lire, affaire de tact"

Jean-Luc Nancy

\section{INTRODUCCIÓ}

Joan Brossa (1919-1998) és una figura clau de l'avantguardisme català de postguerra. La seva obra està profundament arrelada en la cultura catalana i, alhora, compromesa obertament en el diàleg amb els esdeveniments internacionals més innovadors en la poesia, l'art i el teatre del segle xx. Per a ell la poesia era un procés constant de recerca, la qual cosa el portà a estar assabentat de tots els moviments literaris i artístics experimentals que se succeïren en la segona meitat del segle $\mathrm{xx}$.

Malgrat que en els seus inicis publicà poc i que, per tant, no fou realment conegut en el món de la literatura catalana fins a l'any $1970,{ }^{2}$ curiosament fou traduït a d'altres llengües des de ben aviat. ${ }^{3}$ Segurament trobaríem l'explicació en el món ampli de relacions que tingué des del primer moment. El fet de relacionar-se amb Joan Miró i Joan Prats des del 1941, de fundar el grup Dau al Set (1947) amb pintors com Joan Ponç, Antoni Tàpies o Modest Cuixart,${ }^{4}$ de dedicar-se al teatre d'avantguarda i voler portar-lo a l'estranger, ${ }^{5}$ etc. li permeté connectar amb 
persones de diferents països i disciplines (art, teatre, literatura, etc.) que procuraren donar-lo a conèixer fora de Catalunya i que alhora li facilitaren una permanent informació sobre tot allò que es movia a Europa.

La recent catalogació de la correspondència del fons de la Fundació Joan Brossa ${ }^{6}$ ens ha permès apropar-nos als corresponsals estrangers del poeta. La llista és interminable, ${ }^{7}$ i a més, cal tenir en compte que de vegades també s'hi troben esborranys de cartes del mateix Brossa. L'obsessió d'aquest per l'escriptura era gairebé compulsiva i necessitava fer diferents proves abans de donar un text per definitiu, tant si era un poema com una carta. El suport era, però, indiferent $i$, donats els seus pocs recursos, reaprofitava constantment. Qualsevol paper (trossos de diari, sobres, cartes, versions descartades de poemes, etc.) podia ser bo per escriure-hi noves coses. Així doncs, un esborrany citat en aquest treball era escrit darrere del manuscrit d'un poema del mateix any. Podríem dir que d'alguna manera fou un pioner del reciclatge.

Aquesta correspondència permet introduir-nos en els diàlegs i comentaris entre el poeta i un grup d'artistes internacionals, poetes, crítics d'art i intel-lectuals, al voltant d'una àmplia gamma de temes relacionats amb la poesia visual, les publicacions brossianes, les traduccions de poemes o simplement els assumptes personals. En general, ens parlen de les dificultats amb què els escriptors d'avantguarda s'enfrontaven i de les preocupacions que tota creació comporta. Les nombroses idees que hi sorgeixen mostren una forta admiració i amistat amb Brossa.

En alguns casos, hem pogut complementar la lectura amb els esborranys que el poeta feia de les seves respostes, com hem comentat abans, o amb les cartes de Brossa facilitades pels corresponsals. D'altra banda, cal tenir en compte que a partir que Pepa Llopis entrà plenament en la seva vida, era ella la que contestava les cartes en nom dels dos, motiu pel qual els corresponsals de la darrera època (els anys noranta) no posseeixen cartes manuscrites de Brossa sinó de la seva companya. ${ }^{8}$

La correspondència mostra un autor molt ben informat dels diferents moviments d'avantguarda d'aquells anys: lletrisme, poesia concreta, poesia visual, etc. alhora que dissenya una autèntica xarxa internacional de persones interessades per la trajectòria literària, artística i escènica del poeta català.

Aquest assaig és part d'un projecte més llarg que sorgeix de la lectura de les cartes de corresponsals estrangers de Joan Brossa des dels anys 50 fins al final de la seva vida (1998). Donada l'amplitud d'aquesta correspondència, ens centrarem en una visió general de les seves característiques a partir d'una selecció de corresponsals, per després detenir-nos en tres exemples de finals dels seixanta, moment d'expansió i unió dels poetes “experimentals" d'arreu del món. Les cartes es presenten acompanyades de comentaris, notes i il-lustracions de suport. En general, s'ha optat per cartes enviades a Brossa per corresponsals de renom 
internacional que reflecteixen la cultura de l'època així com la seva colllaboració i admiració pel poeta. La tria s'ha centrat en les cartes de João Cabral de Melo, Jacques Dupin, Alain Arias-Misson, Adriano Spatola, Felipe Boso, Roland Penrose, Julie Lawson, Julien Blaine, Sarenco, Klaus Peter Dencker i John London. Aquests documents són de gran vàlua per a una cronologia completa i precisa de les activitats de Brossa. A més, molt sovint, contenen observacions personals que donen una mica de llum sobre la personalitat i les amistats sòlides d'aquest poeta i artista excepcional.

\section{ELS PRINCIPALS CORRESPONSALS ESTRANGERS DE LES DIFERENTS DĖCADES DE TREBALL BROSSIÀ}

Els corresponsals estrangers pertanyen a èpoques molt diferents de la trajectòria del poeta barceloní. El primer que destaca en els inicis de l'època de Dau al Set és João Cabral de Melo Neto, que treballava al consolat de Brasil a Barcelona. A les seves converses amb Lluís Permanyer, Brossa diu:

No recordo qui em va presentar Cabral; el que tinc present és que el vaig descobrir tard, perquè ja feia temps que era a Barcelona. [...] La primera exposició dels pintors del Dau al Set, a l'Institut Francès, va ser presentada amb un text seu. ${ }^{9}$ Cabral ens va reafirmar en el surrealisme, però ens va aconsellar que li apliquéssim un compromís social. Ell ens va descobrir el marxisme. [...] I per iniciativa seva em va publicar el meu primer llibre: Sonets de Caruixa, selecció de poemes feta per ell mateix. De fet, va demostrar que creia en mi i se la va jugar, mentre que hi havia altres persones que només enraonaven ... Aquella demostració em va agradar molt. Quan Rafael Santos Torroella va editar Em va fer Joan Brossa, en Cabral es va oferir a escriure el pròleg. (Permanyer 86)

Cabral fou, doncs, la persona que produí el gir cap a la realitat de l'obra de Brossa. Aquest li traduí del portuguès uns poemes per al Dau al Set de juliol-agostsetembre del 1949 i sempre el tingué en gran consideració. I, per la seva banda, Cabral li publicà una part de Sonets de Caruixa l'any 1949 i li escriví el pròleg per a Em va fer Joan Brossa el 1951. S'escriviren el 1950 i el 1951, durant l'estada de Cabral a Londres. En una carta des d'aquesta ciutat (A.JBR.00372; 8 gener 1950), ${ }^{10}$ Cabral diu:

Tinc molta curiositat en l'antologia de Salvat-Papasseit. I molta en el llibre que Santos [Torroella] editarà. Tinc fins i tot bastants esperances en la vostra colllaboració i de Santos. Santos conserva en la seva essència el millor esperit realista i humanista de l'Espanya d'abans de la guerra. I aquest esperit no ha desaparegut: potser estigui una mica adormit.

De la colllaboració de tots vosaltres pot sorgir un grup fecundíssim: un grup realista i humanista (no en el sentit de l'humanisme universitari, sinó de la confiança en l'home). 
I aquest grup pot ser decisiu en l'hora actual. Per una banda s'afirmarà contra tots els existencialismes, surrealismes, magicismes, negadors de la realitat i de l'home. I per una altra banda s'afirmarà contra tots els fabricants de sonetets, odetes gregues, amb floretes, casetes i hortets (Riba, etc. $)^{11}$

Cabral tenia clar, doncs, que aquell grup s'imposaria. La seva mirada forana podia veure-hi molt més que les capelletes del moment i l'ambient advers a la poesia i art que Dau al Set practicava.

Tot i que després s'allunyaren per la distància, ja que el poeta brasiler recorregué diferents ciutats europees fins que tornà al Brasil, sempre es recordaren mútuament i estigueren informats del que feien un i l'altre fins al retrobament a Rio de Janeiro l'any 1993, amb motiu de la presentació de l'“Enciclopédia Virada do Século" que homenatjà tres Joans: John Ashbery, Joan Brossa i João Cabral (Figura 1).

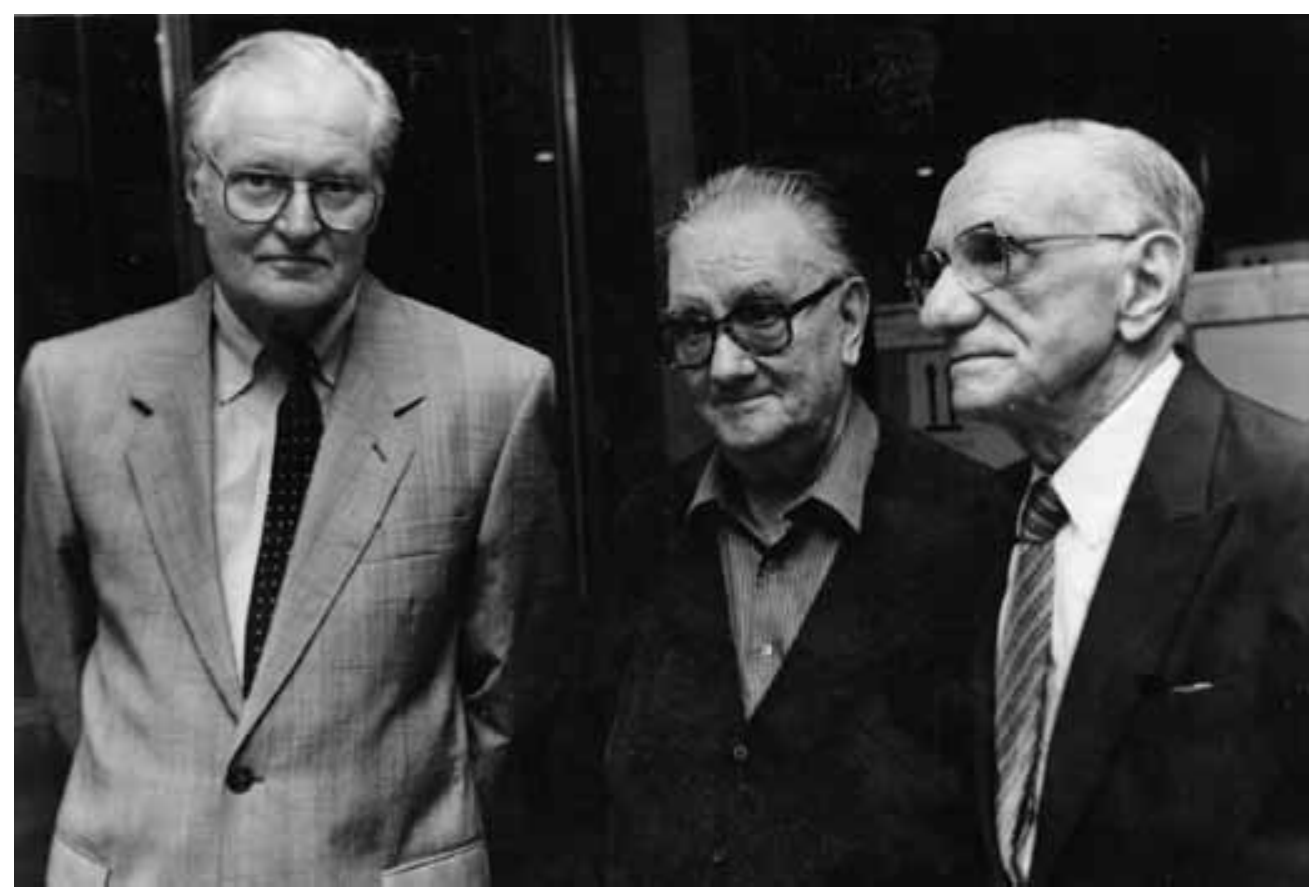

FIGURA 1. John Ashbery, Joan Brossa i João Cabral a Rio de Janeiro, 1993 Fotògraf: Dary Cardoso. ${ }^{12}$

Els anys seixanta representen el coneixement de Brossa per part de la poesia experimental europea: Alain Arias-Misson, Adriano Spatola i Felipe Boso, els tres corresponsals que hem seleccionat per comentar-ne una mica més detingudament la relació a l'apartat següent en serien els més representatius, però també és el moment 
de relacionar-se amb altres personatges del món artístic com Jacques Dupin, per exemple. El contacte és conseqüència de l'amistat de Brossa amb Miró, al qual coneixia des del 1941 i amb qui s'escrivia des del 1943 quan no era a Barcelona. El poeta enviava textos i poemes plàstics a Miró, en l'opinió del qual confiava cegament. L'any 1960 representa l'inici de les colllaboracions entre els dos, ja que, arran de l'exposició "Poètes, peintres, sculpteurs" a la Galeria Maeght de París, Miró convidà Brossa a participar-hi amb un poema. La revista Derrière le miroir publicà en el seu número 119 una litografia del pintor acompanyada del text de Brossa. L'1 de maig de 1960 Jacques Dupin escriu a Brossa (A.JBR.02334) dient-li que, tot i que Joanet Artigas ja li ha escrit, ell també ho fa perquè és urgent tenir el poema ja que la revista i l'exposició seran a primers de juny. Li demana que enviï també còpia del poema a Miró perquè pugui començar a treballar en el projecte de litografia i acaba comunicant-li que està molt content de ser a l'origen d'aquest projecte i de poder publicar un poema de Brossa a França. El 25 de maig hi ha una altra carta (A.JBR.00386.001), que té força interès des del punt de vista de la traducció. Transcrivim a continuació la traducció al català (des del francès) de la carta:

\section{Estimat Brossa,}

He rebut bé el teu poema per a Derrière le miroir. És perfecte per acompanyar Miró. Hem intentat, amb Joanet Artigas, de traduir-lo. Això ha estat del tot impossible. Treballes ${ }^{13}$ d'una manera $\tan$ forta $i \tan$ pura amb el mateix geni de la teva llengua que un equivalent francès és impossible. Hem pres, doncs, la decisió de publicar-lo en català, sense traducció. Espero que hi estaràs d'acord. Si no, proposes tu?

Ben cordialment, Jacques Dupin

S'expressen, doncs, ben clarament, les dificultats que la llengua de Brossa sempre ha tingut per als traductors. John London (136-43) ho ha comentat tot resseguint els encerts i fracassos de traduccions a diferents llengües per part de traductors avesats a aquesta feina. Per això, Brossa preparà la resposta següent: ${ }^{14}$

Estimat Dupin,

Publicar el poema en català sense traducció és llàstima. Seria incomprensible per a la majoria de la gent. Esforç inútil i sense cap missatge.

Proposo una traducció en "prosa". I enviar una còpia a Miró per conèixer la seva opinió.

Comprenc que és difícil traduir però crec que caldria intentar-ho, almenys d'aquesta manera.

Gràcies per tot i el meu record per a Joanet i tota la meva amistat per a vós.

M'agradaria també que Prats conegués la traducció. Seríeu tan amable d'enviar-li també una còpia. ${ }^{15}$ 
Una tercera carta de Dupin del mes de juny del mateix any (A.JBR.02335) ens dóna a conèixer el resultat: una edició del poema ${ }^{16}$ en francès amb algun canvi fet per Dupin al darrer moment. No obstant això, promet d'esmenar-ho a l'edició següent si el poeta no hi està d'acord. Però l'opinió de Brossa fou una altra. Així ho expressà en el text "Rellotge del vent", escrit per a la celebració del centenari de Miró l'any 1993:

Tots sabem el xovinisme dels francesos, la cultura dels quals algú va definir de "mediocritat brillant". Doncs bé, el 1960, arran de l'exposició "Poètes, peintres, sculpteurs", Miró em va demanar un poema per acompanyar un gravat seu. En aquest cas el desengany va venir del traductor. El poema feia al-lusió a un maquillatge de teatre amb un contrapunt final. I aquí ve el problema. El traductor francès, poeta i crític d'art [...], va rebutjar l'encàrrec perquè opinava que la "barreta de color carn" és un terme massa vulgar per a figurar en un poema ... I tot de coses per l'estil. La traducció, la va haver de fer a corre-cuita en Joanet Gardy-Artigas i, si no arriba a ser per la insistència de Miró, jo hauria estat bandejat de l'exposició. Per venjar-se, a Derrière le miroir, entre el meu poema i el gravat de Miró, hi van posar un poema de Quenau. (També recordo que el 1961 un poema meu per a l'exposició "Peintures murales de Joan Miró" inexplicablement va sortir sense traducció francesa ... Però Prats i Miró sempre em deien que no em desanimés ....) (Brossa, Prosa completa 650-51)

Tot sovint el tema entre els corresponsals és el de la traducció, però no sempre hi ha discussió com en aquest cas, ja que si es tractava d'un professional i d'una llengua que Brossa no coneixia, tot es limitava als comentaris dels traductors.

De la dècada dels setanta, destaquem també una altra personalitat artística: Roland Penrose, una de les principals autoritats en Picasso i Miró. A través d'aquest darrer, es convertí en un admirador de l'obra de Brossa i el visità diverses vegades a Barcelona. El crític estava en contacte amb alguns artistes catalans clau (com el mateix Miró i Tàpies) i editors com Manuel de Muga, una figura líder en publicacions d'art i fundador de la Galeria Joan Prats. En una carta escrita en francès, de data 10 de maig de 1973 (A.JBR.03355.099), Penrose diu que ha rebut l'Oda a Joan Miró de Brossa a través de Muga i li dóna les gràcies efusivament per l'esplèndid llibre. Aquest era una suite de poesia visual realitzada pel poeta l'any 1969, que fou editada amb un pròleg i epíleg plàstics de Miró el 1973 (Figura 2). Es tracta d'un homenatge al pintor.

Com el mateix Brossa comenta al text de presentació del llibre, la protagonista aquí és la lletra M, i concretament les lletres de la paraula Miró. El fet que el cognom "Miró" es pugui relacionar amb el verb "mirar" (encara que etimològicament siguin molt distants) i que la paraula "mirall" sigui un derivat del mateix verb, dóna lloc a una sèrie de jocs i escamotejos de lletres. Al seu torn, Miró realitzà per al llibre un "prefaci i una cloenda ambientals". En paraules de Brossa: 
Per a aquesta oda l'autor ha triat un altre codi que el literari. Cap somni en veu alta, sinó un testimoni. [...] Les lletres no tenen cap mot precís i l'esforç indecís de mirar per la finestra desvetlla deleres. Aquí la lletra $M$ es val d'ella mateixa com a mitjancera d'una expressió. En traspassar el límit dels mots, les suggestions perden el límit, i la tenacitat del missatge testimonia el desmai d'una pàgina blanca. Alliberades les lletres, ¿quina imatge supedita, doncs, perfum i mormol? [...] Les suites de Miró, concebudes a l'hora d'estructurar el llibre, voregen el clos del poema a tall de prefaci i de cloenda ambientals. (Brossa, Prosa completa 320-21)

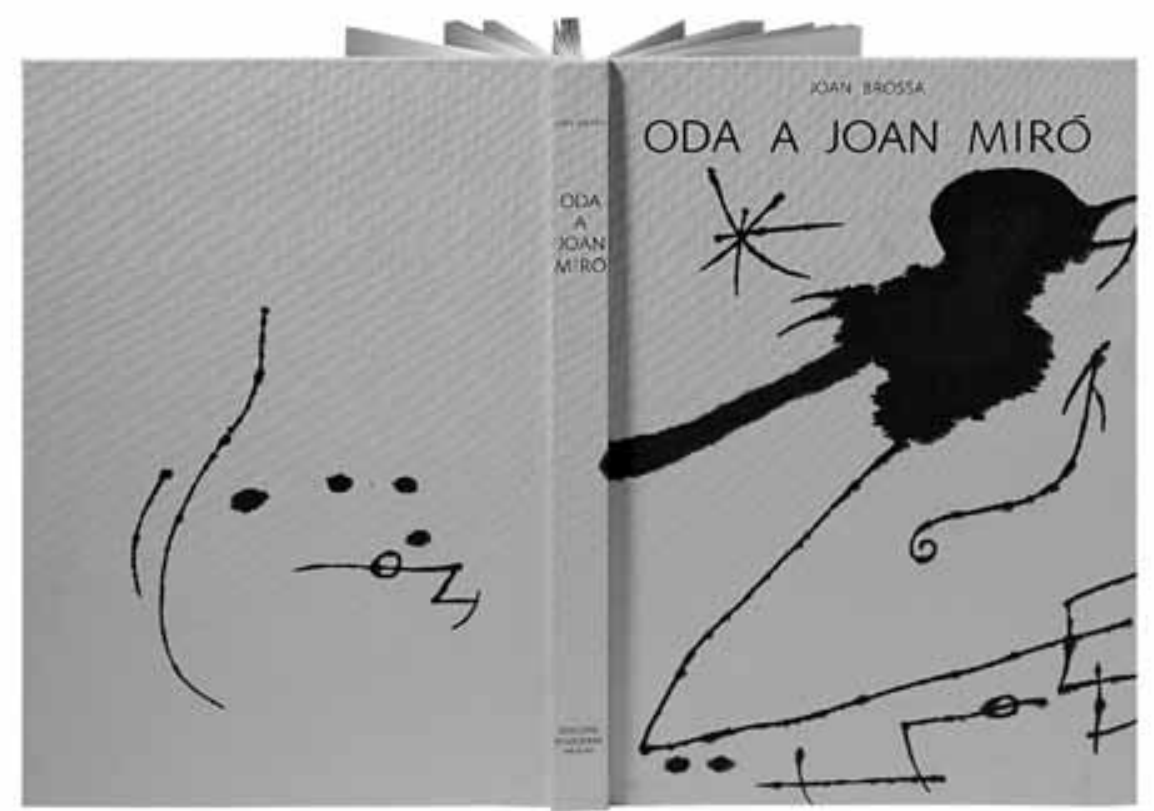

FIGURA 2. Coberta del llibre Oda a Joan Miró (1973) de Joan Brossa i Joan Miró

El nom de Joan Miró apareix molt sovint en la correspondència de Brossa. Val la pena esmentar en aquest context que, en un text escrit el 9 de febrer de 1993 per celebrar el centenari del naixement de Miró, titulat “Miró, sempre”, Brossa escriví:

Hi ha artistes que es valoren per la seva amplitud; contràriament, Miró s'ha dedicat a enfondir el seu pou. [...] Creador del seu propi llenguatge, Miró no deixa de tenir els peus a terra en traçar el vol dels ocells. Per això sempre serà actual. La gran espiral de la seva obra no perdrà mai aquesta condició. Considero la millor sort de la meva vida haver treballat amb Miró i haver tingut accés a la seva obra, de la mà de Joan Prats. Miró i Prats van ser els primers a encoratjar-me en el laberint de la poesia visual. Són coses que no s'obliden. (Brossa, Prosa completa 698) ${ }^{17}$ 
La carta de Penrose a Brossa revela el respecte profund que li tenia a Brossa, i l'estimació artística i personal pel gran mestre Miró i el seu deixeble avantatjat. Cal recordar que el mateix any de la carta, Penrose realitzaria el pròleg de l'esplèndid llibre de Brossa i Tàpies, Poems from the Catalan, amb litografies d'Antoni Tàpies i, poc després, el 1978, del llibre de Brossa de Poemes objecte, que facilitaria el coneixement d'aquesta faceta artística del poeta.

El reconeixement internacional de Brossa s'inicià en els vuitanta, i més especialment el 1986, quan se celebrà la primera gran exposició de la seva obra a la Fundació Joan Miró de Barcelona. Aquesta mostra, d'àmplia repercussió pública, aplanà el camí per a la magna antològica al Reina Sofia de Madrid el 1991, així com per la projecció internacional a gran escala, com ho demostra l'exposició al Riverside Studios de Londres el 1992.

En relació amb aquesta darrera exposició, destaquen dues cartes ${ }^{18}$ de Julie Lawson (A.JBR.03352.002.017 i A.JBR.01253), assistent personal de Roland Penrose i curadora de The Elephant Trust Foundation, una institució fundada el 1975 per Penrose que tenia com a missió l'educació pública en tots els aspectes de les arts i la promoció de tot el que fos experimental, no convencional i imaginatiu. La primera carta, de data 9 de juliol de 1988, dirigida en anglès a Pepa [Llopis] i Joan [Brossa], parla de la planificació d'una exposició de l'obra de Brossa a Londres, li demana consell al poeta, ja que ella no ha vist mai una exposició de la seva obra i els informa del seu proper viatge a Barcelona, per veure l'obra de Brossa. Li pregunta si en aquells moments hi ha alguna mostra en algun lloc, de manera que els patrons de la Fundació anglesa puguin veure el seu treball. Lawson hi insisteix perquè d'ells depèn l'aprovació i la col-laboració en la mostra de Londres. Com a comissària d'art amb molts anys d'experiència, Lawson necessitava desenvolupar, com remarca a la carta, un pla minuciós on es descrivís amb claredat el contingut de l'exposició, els objectius i els costos. Com que la carta és en anglès i Lawson sabia que ni el Joan ni la Pepa l'entenien acaba dient que una persona propera a tots i que coneixia bé aquella llengua "us ho explicarà tot".

No fou, però, fins al 1992 que l'exposició de Brossa a Londres es convertí en una realitat. En la carta A.JBR.01253 de 7 de novembre de 1992 i com a fideïcomissària de The Elephant Trust, Lawson escriu a Brossa sobre els plans per al viatge d'ell i Pepa a Londres. Els proporciona el nom de l'hotel (Pembridge Court Hotel), així com els horaris d'activitats, entre les quals hi ha la roda de premsa o la inauguració de l'exposició per part de l'ambaixador espanyol. Lawson hi afegeix: "Després, hi haurà un sopar per a vosaltres i els vostres amics i convidats, incloent-hi Arthur Terry, ${ }^{19}$ John London, Hausson ${ }^{20}$ i Robert Clark", ${ }^{21}$ noms clau en el context de la xarxa de contactes de Brossa. Al final de la carta, Lawson s'ofereix per ensenyar-los tot allò que vulguin veure a Londres i els comenta que els farà una llista de possibles coses a fer. Acaba dient: "Moltes gràcies a tots per l'ajuda que 


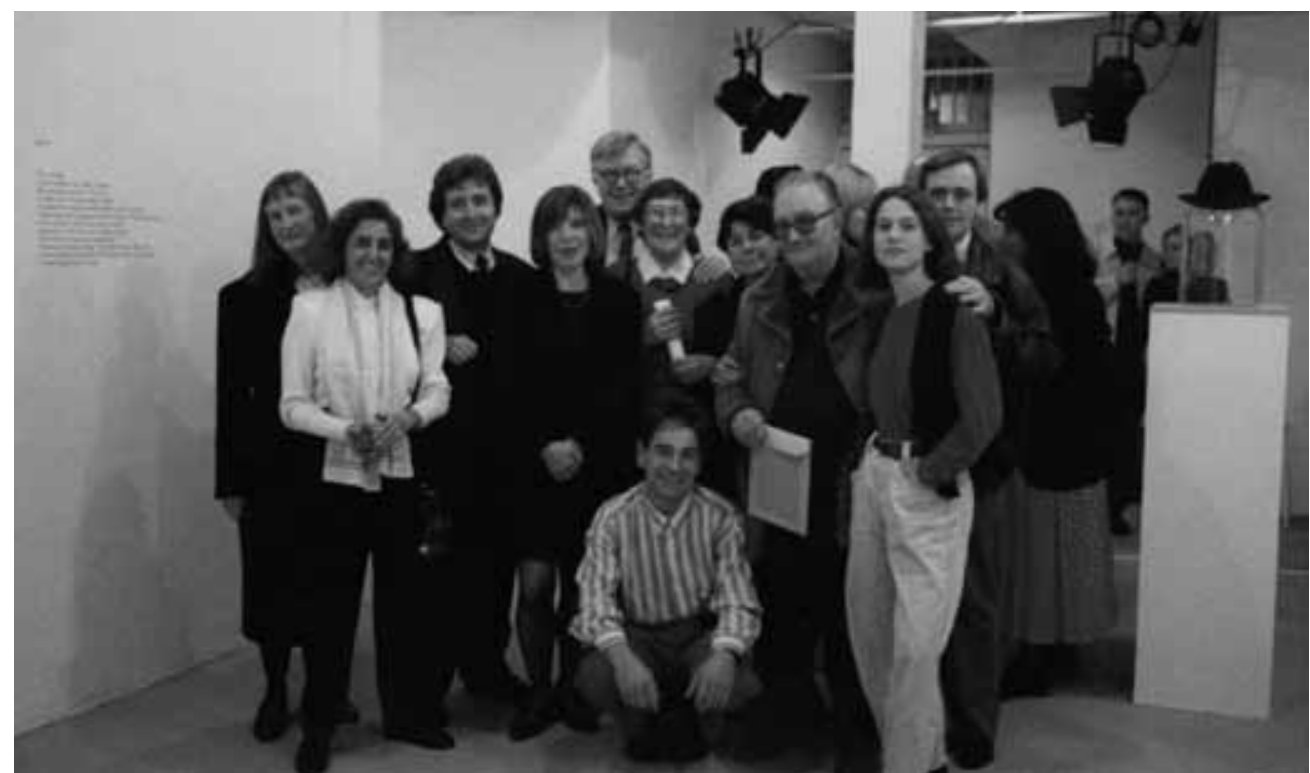

FIGURA 3. Inauguració de l'exposició de Brossa al Riverside Studios l'any 1992.

Fotògraf: desconegut. Entre d'altres i començant per l'esquerra, Julie Lawson, Jaume Josa, Arthur Terry, Jordi Jané, Pepa Llopis, Joan Brossa i Hausson (Jesús Julve)

m'heu donat i per la vostra generosa hospitalitat. Tots estem molt entusiasmats amb l'exposició i esperem que aproveu la presentació". ${ }^{22}$

Brossa començà a rebre més i més invitacions per donar xerrades, llegir poemes o fer exposicions. Entre els corresponsals d'aquesta època, volíem destacar-ne tres poetes experimentals de relleu. En primer lloc, Julien Blaine, ${ }^{23}$ poeta francès i editor internacionalment conegut en el camp de la poesia experimental, que li escriu des de Marsella el 23 de març de 1990 (A.JBR.03356.129), per convidar-lo a exposar a "Le Refuge" del Centre International de Poésie Marseille, que ell mateix havia creat l'any 1989. Blaine volia que Brossa fos un dels primers convidats d'honor del centre i a la carta li diu que ha programat la seva visita per al 4 de maig de 1990. Reconeix que el termini és potser massa curt i es compromet a canviar la data si cal. D'altra banda, proposa a Brossa que triï el tipus d'activitat que li agradaria fer: donar una xerrada, fer una presentació d'algun llibre o treball seu o participar en una taula rodona. Blaine també li comunica que serà a Barcelona a l'abril, però que li agradaria de comptar amb l'acceptació de Brossa abans de veure'l en persona.

Pepa escriví en llapis a la mateixa carta que li havien contestat l'1 d'abril dient-li que Brossa no podia anar-hi. No obstant això, els esforços de Blaine es veieren compensats tres anys més tard amb l'exposició que Brossa realitzà del 12 de febrer al 17 d'abril de 1993 a "Le Refuge" i la realització d'un poema visual ben significatiu com a cartell de la mostra (Figura 4). 


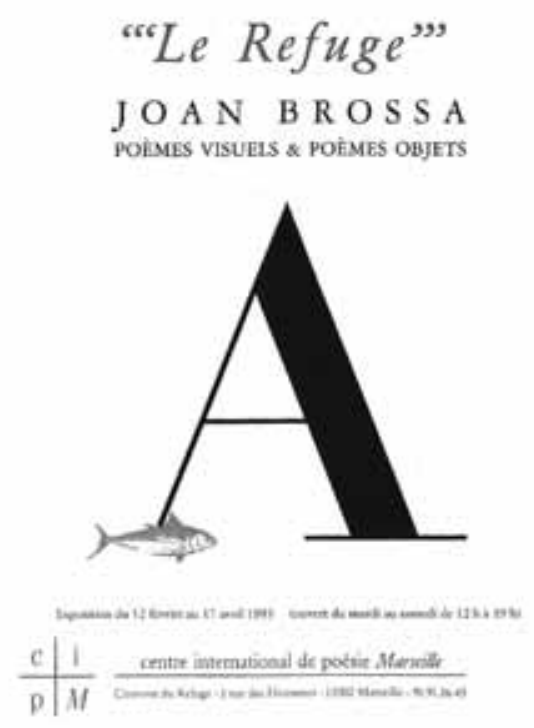

FIGURA 4. Cartell de Joan Brossa "Le Refuge" per al Centre International de Poésie de Marseille, 1993

Un altre dels factòtum de la poesia experimental europea, l'artista italià Isaiai Mabellini (àlies Sarenco) ${ }^{24}$ també admirà i colllaborà amb Brossa. Entre les cartes enviades a Brossa, en destaquem dues, escrites en francès, datades a Verona, el 21 i 23 d'abril de 1994 (A.JBR.03359.095.001 i A.JBR.03359.095), en les quals convida Brossa a participar en un dossier dedicat a la poesia concreta i visual que ell i Julien Blaine estan preparant per a l'editor Adriano Parise. Li demana dos originals de poemes visuals dels anys $60 \mathrm{i}$ dels 90 per al projecte. Curiosament, un dia més tard, abans d'haver enviat la seva carta, Sarenco rebé un paquet de la Galeria Joan Prats, amb dues reproduccions fotogràfiques dels objectes "Nocturn I", del 1967, i "Yacht", del 1990. En la carta del 23 d'abril li expressa, doncs, la seva sorpresa i amb un sentit de l'humor ben enginyós, suggereix que potser Brossa ha llegit la seva ment i la de Blaine. Aquesta carta ens recorda un comentari semblant d'AriasMisson (en la seva carta de 3 de febrer de 1967), que després comentarem.

Tot seguint dins de la poesia experimental europea, voldríem destacar un tercer corresponsal dels anys noranta: Klaus Peter Dencker ${ }^{25}$ el qual té una llarga història de colllaboració amb poetes visuals catalans. En una carta mecanografiada del 5 de gener de 1995 (A.JBR.03360.201) es dirigeix a "Estimats amics i artistes de la Poesia Visual", convida els poetes a participar en un nou projecte d'una enciclopèdia de Poesia Visual i els sol-licita alguns materials. A la carta general, però, hi ha una nota escrita a mà, també en anglès, en què Dencker expressa a l'“estimat Joan”, la 
seva preocupació per algunes trucades telefòniques que ha rebut de persones que es presenten com a ajudants de Brossa i li demana aclariments sobre la qüestió. Dencker deixa clar que ell sempre es comunica directament amb els poetes visuals, sense intermediaris. Per això, li demana material original per al seu projecte $i$ sol-licita la seva comprensió. És probable que durant aquells anys els ajudants dels galeristes que portaven l'obra de Brossa ${ }^{26}$ volguessin col-locar peces de Brossa a l'estranger. Tanmateix, gràcies a una nota manuscrita de Pepa Llopis que figura darrere de la carta de Dencker sabem que el poeta envià un exemplar de l'"Elegia al Che" de l'edició del 1971; un d'“Espanya", de l'edició de la carpeta Septet visual del 1978 i un tercer anomenat "Poema", també del Septet visual.
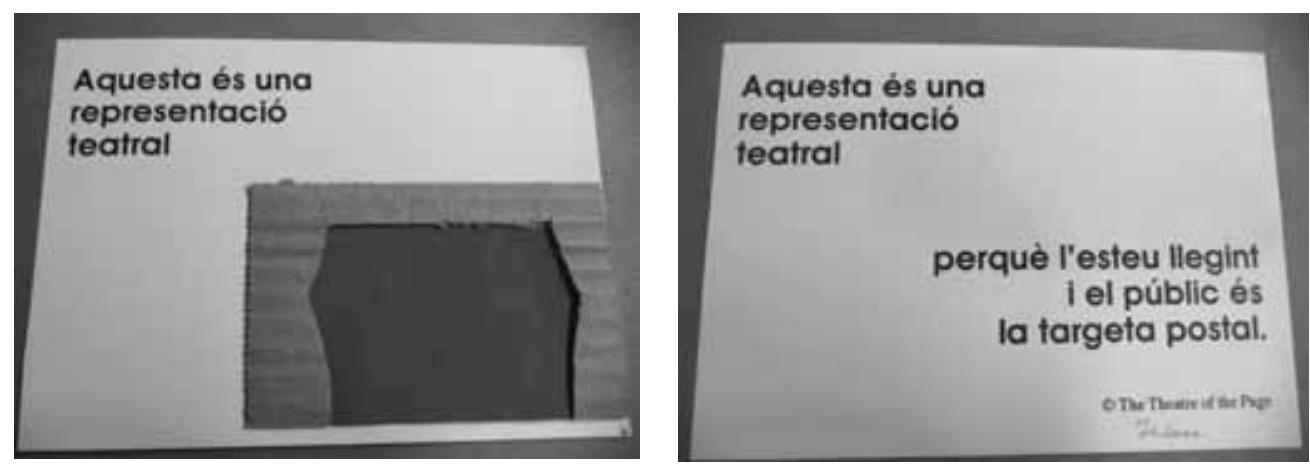

FIGURA 5 i 6. Carta postal 26.06.1997 (A.JBR.01233) "El teatre de la pàgina"

La correspondència de Brossa no només és plena d'informació sobre la vida intellectual del poeta català i els seus corresponsals, sinó que també és, en ella mateixa, un magnífic material visual (per exemple: dibuixos, curioses targetes postals, collages, fotografies, invitacions d'exposicions, art electrònic). Entre les cartes i postals més originals que trobem a la col-lecció hi ha les escrites per John London. Les més de trenta cartes mostren una gran simpatia cap a Brossa i Pepa, i contenen informació interessant sobre les relacions entre ells, però alhora són particularment enginyoses i inusuals, visualment parlant.

London començà a escriure a Brossa el 1992. En aquell moment, ell era un estudiant i un gran admirador del poeta català i tenia la intenció d'escriure un article sobre ell per a The Times de Londres. El seu pont per contactar-hi fou l'hispanista anglès i amic de Brossa Arthur Terry. London, dramaturg, crític d'art i professor d'anàlisi de performances i de teatre, es convertí en un dels principals experts de l'obra de Brossa, com ho demostra el seu llibre publicat a Barcelona l'any 2010, del qual hem parlat abans.

Ens agradaria comentar aquí en particular una postal molt amable de John London escrita el 12 de desembre de 1996 des de Mumbles Pier, Gal-les 
(A.JBR.01231). Agraeix a Pepa la seva carta del 12 de novembre, amb una nota per a David George, ${ }^{27} \mathrm{i}$ expressa el seu interès per una obra en polonès sobre Brossa. ${ }^{28}$ Però sens dubte, la part més fascinant és la que segueix:

Penso que puc entendre la vostra frustració amb la "pressió" cultural dels joves que volen que Joan els digui una cosa (sobretot, o potser, només positiva) sobre la seva obra. Però és una mena de respecte pel "avi" de la cultura catalana.

Tot això ho dic perquè jo també us envio coses ... I m'interessen els vostres comentaris.

Aquestes paraules ens manifesten que les idees i els treballs innovadors de Brossa eren d'extraordinària importància i tot un referent per a les noves generacions de poetes visuals i dramaturgs no només a Catalunya o a Espanya, sinó també a la resta del món.

L'esdeveniment "Creativitat ara" celebrat a l'Alfàs del Pi, l'any $1996,{ }^{29}$ en què London també participà, representa l'eclosió d'una colla d'artistes, poetes, crítics i traductors estrangers que quedaren fascinats per la personalitat de Brossa.

\section{TRES EXEMPLES}

Un moment especial en la correspondència brossiana, el representa el període de finals dels anys seixanta i principis dels setanta. Coincideix amb l'època en què Brossa es llença a tot tipus de creacions experimentals: la poesia visual més enllà dels experiments plàstics dels anys cinquanta, els poemes objecte, els fregolismes, les accions musicals, els stripteases i el teatre irregular. ${ }^{30}$ D'aquest moment hem triat tres persones de diferents països, les quals esdevingueren representatives del que fou el moviment de la poesia experimental d'aquells anys.

\subsection{Alain Arias-Misson}

El 3 de febrer de 1967, ${ }^{31}$ l'artista i intèrpret belga-americà Alain Arias-Misson escrivia a Brossa des de Madrid en un "català" ben particular:32 "amic Joan, acabem de rebre la teva carta. Oi, es psyquic! jo vaig escriure la meva fa dos dies, i la nela la va posar avui mateix al correu. o sia, que vam escriure al mateix temps".

La carta revela les experiències d'Arias-Misson amb la creació artística madrilenya d'aquells anys i expressa les seves frustracions amb la crítica:

El Madrileño no té la imaginació aberte. Treballam molt aillats açi, estrangers i Americas! Tot el meu treball es publica fora, i ni m'interesa açi. Un amic ingles em diceva el altre dia que devriem viure més al'“español” ... No ens interesa, la creació, aquest món interior, de la imaginació. 
A la mateixa carta, Arias-Misson parla del seu treball: "ara sobretot faig objects poems tinc dos sobre la alquímia, crec que t’agradarán. T’enviaré un photopoem aviat, per a donarte idea".

Interessat a donar a conèixer l'obra de Brossa als Estats Units, Arias-Misson traduí alguns dels seus poemes i els publicà a la Chicago Review, on Leonard Shaykin era l'editor. ${ }^{33}$ Entusiasmat per l'obra del poeta català, Arias-Misson diu:

Props del teu treball va comprenyer bé la meva ultima carta? Aquest Shaykin entén bé el mon dels editorials Americas, diu que es podria fer una cosa molt interessant amb una obra teva - jo li havia parlat de aquesta tan extraordinària de Fregoli — m'avias dit que endemés en Tapies feia algunes illustracios? ${ }^{34}$

Ara aquest mateix $\mathrm{O}$ o $\mathrm{U}$ amb les illustraciós de Pons jes podria suggerir al editor (New Directions o Grove Press) del cual t'havia escrivit? Son els mitjors.

El que es recrea a través d'aquestes cartes és, especialment, el clima literari d'uns temps difícils per a artistes com Arias-Misson i Brossa. Tot i viure en circumstàncies polítiques i culturals adverses durant molts anys, Brossa creà un corpus radical d'obra literària i visual de magnitud notable sense cap mena de concessió, i això és el que meravellà Arias-Misson. ${ }^{35}$ La correspondència revela un clima d'intercanvi amb molts paral-lelismes creatius i un interès mutu. A part de les cartes del Fons Joan Brossa, disposem en aquest cas de la còpia de tres cartes de Brossa que l'artista belga envià recentment a la Fundació Joan Brossa. Tot i que, com és habitual en Brossa, les cartes no estan datades, les informacions proporcionades (sobre la pel-lícula No compteu als dits, realitzada amb Portabella el 1967, la preparació del llibre Frègoli - que sortiria el 1969 — o la publicació de poemes de Brossa a la revista Malebolge el 1967) permeten situar sincrònicament els diferents fronts creatius i els interessos de Brossa. ${ }^{36}$

\subsection{Adriano Spatola}

Un dels llibres brossians que Arias-Misson i els altres corresponsals coneixien era Poemes civils (escrit el 1960), un poemari que, a diferència de molts anteriors tingué la sort de ser publicat un any després d'haver-lo escrit, amb un aiguafort de Joan Miró i coberta d'Antoni Tàpies. Aquesta edició degué impressionar Adriano Spatola, un dels grans innovadors europeus en poesia experimental, creador del manifest "Vers la poesia total" i membre de la gran comunitat internacional de poetes sonors i visuals, que, com Julien Blaine i Alain Arias-Misson sempre admiraren el poeta català. Spatola traduí una selecció de Poemes civils per a la revista Malebolge d'Itàlia. Un testimoni d'aquesta colllaboració n'és una carta del 4 de novembre de 1967, escrita des de Parma, en francès (amb la introducció en castellà), que ens porta a un detall personal sobre el fill de Fregoli, el gran transformista italià, a qui Brossa sempre admirà. En aquest sentit cal recordar que 


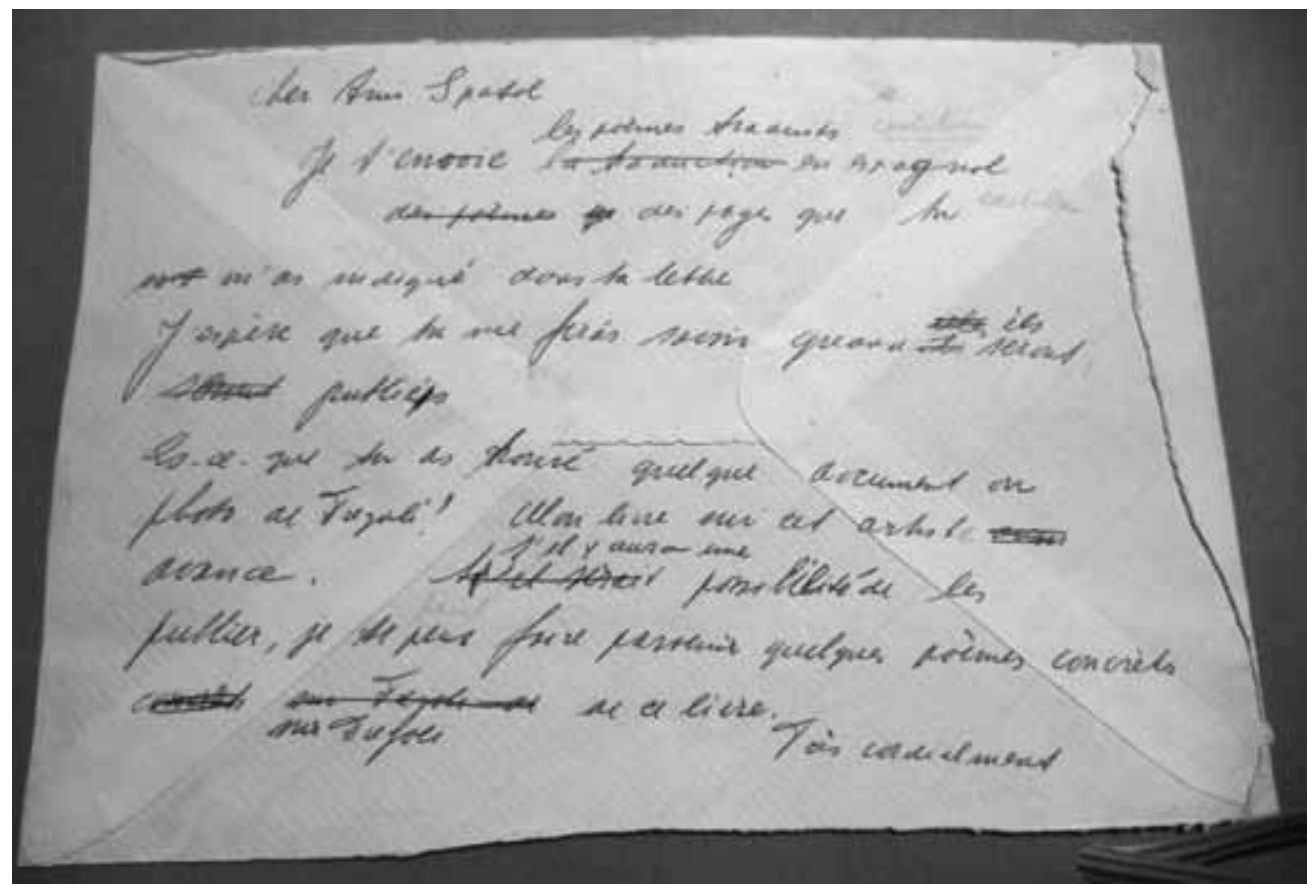

FIGURA 7 Esborrany de carta de Brossa a Spatola al darrere d'un sobre.

Brossa l'any 1965 escriví dos llibres de poemes dedicats a “Fregoli” i també un conjunt de fregolismes. A partir d'aquest material i de la documentació que havia pogut recollir sobre el mite, realitzà el llibre d'artista Frègoli junt amb Tàpies l'any 1969. Per això, Spatola, després d'acusar la rebuda dels poemes per a la revista, diu ${ }^{37}$

Pel que es refereix a fregoli, coneixes el seu fill? es diu arthur pétronio - vet aquí la seva adreça [...] pots escriure-li de part meva, però cal que diguis: "adriano spatola, amic d'arrigo lora totino" (no sé si ell es recordarà de mi).

En tot cas escriuré a totino, i ell escriurà de seguida a pétronio.

Espero tenir novetats teves, al més aviat possible.

Fins aviat, amic estimat

Adriano Spatola

Per sort, entre els papers de Brossa dipositats al Macba, s'ha trobat un esborrany (A.JBR.00773.096) del que degué ser la carta de Brossa a la qual Spatola dóna resposta. Després de dir-li que li envia els poemes que ell li havia demanat i de pregar-li que li faci saber quan seran publicats, li diu el següent: "Has trobat algun document sobre Frègoli? El meu llibre sobre aquest artista avança. Si hi ha alguna possibilitat de publicar-lo, et faré arribar alguns poemes concrets sobre Frègoli d'aquest llibre". 
Adriano Spatola morí aviat (1988), però, dins de la correspondència brossiana hi ha algunes cartes de la seva vídua, Bianca Maria Bonazzi, la qual escriví a Brossa l'any 1993 (A.JBR.03356.131) explicant-li que el mateix dia que Spatola morí rebé un catàleg d'exposició de Brossa que la reconfortà en aquell moment tràgic. Ara es proposava de seguir una part de l'activitat del seu marit i, atès que Spatola admirava l'obra del poeta català i, de fet, tenia el projecte d'organitzar una exposició amb obra de Brossa en un espai del seu domicili reservat a l'activitat expositiva, Bonazzi proposava a Brossa de reprendre aquest projecte i li demanava poemes per a la revista Tam Tam, de la qual li trametia tots els números de la col-lecció apareguts a partir del $1986 .{ }^{38}$

\subsection{Felipe Boso}

Un tercer corresponsal que volem destacar és Felipe Boso. Aquest poeta espanyol estava establert a Alemanya des dels anys cinquanta. Aquí conegué Eugen Gomringer, un dels creadors de la poesia concreta, la qual cosa li obrí nous camins poètics que el portaren a la poesia visual. Com a poeta, traductor i crític, Boso jugà un paper molt important en la divulgació internacional de la poesia experimental que es feia a Espanya. Publicà des d'Alemanya seleccions de poesia experimental en diferents revistes com ara Poesía Hispánica. En una carta datada el 31 de desembre de 1971 Boso diu a Brossa el següent:

Se me ofrece - me han ofrecido - la oportunidad de publicar en Poesía Hispánica una breve selección ( $8-10$ poetas) de poesía experimental. De cada poeta se publicará un trabajo. Todos tienen que ser inéditos.

Tú figuras, por derecho propio, en mi plan. [...] No quiero encarecerte el significado que para la experimentación poética en España tiene esta publicación, que supone, por fin, su reconocimiento por parte del "establishment" literario español, sin olvidar su proyección en América Latina. El hecho no tiene tanta importancia en sí - al fin modesta - como en sus implicaciones y derivaciones. No creo que para ti tenga tanta importancia. La tiene, sí, para todos los experimentadores. A la hora de decidirte piensa, pues, en colectivo. Como de esta primera presentación oficial depende tanto te ruego que me mandes lo mejor que tengas a mano. Gracias en nombre de todos los demás seleccionados, que somos Millán, Cirlot, Castillejo, Viladot, Gradolí, Molero, Gómez de Liaño, Montells y yo.

La antología de Akzente saldrá, en número monográfico, el próximo mes de junio. Los tres primeros poemas de la misma son "Élegie pour la Che", "Nocturne" y "Comunication".

Veiem clarament l'admiració que Boso tenia per Brossa i com, d'alguna manera, el considerava per sobre dels altres. Cal destacar els tres poemes que finalment sortiren a la revista Akzente: el primer és el cèlebre "Elegia al Che". Aquest poema fou dissenyat per Brossa l'any 1967, immediatament després de la mort del Che, i forma part d'una suite de poesia visual inèdita, Llibre de. Fou un dels poemes 
publicats a Quadern de poemes, llibre publicat en francès ${ }^{39}$ amb el títol dibuixat per Antoni Tàpies i traduït per Anne-Marie Comert. L'any 1971 fou editat per primera vegada dins dels Vuit pòsters poema i fou un dels exposats a l'exposició de la Petite Galerie de Lleida aquell mateix any. Posteriorment seria reeditat a la carpeta Septet visual.

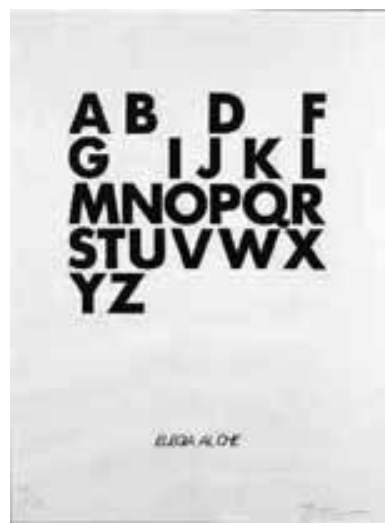

FIGUR A 8 Joan Brossa, "Elegia al Che” (1967-1978)

$\mathrm{Al}$ seu costat, a Akzente aparegueren dos poemes més, que també formaren part de Quadern de poemes: "Nocturn" i "Comunicació", dins del tipus de poesia que Brossa practicava des d'Em va fer Joan Brossa de l'any 1950, en el sentit de captació de la realitat del carrer o de crítica irònica dels suposats progressos de la humanitat.

En una altra carta del 1973, Boso demana poemes visuals a Brossa com una A que ha vist a l'Hospitalet i que segurament es tractava del poema "Desmuntatge". Els seus mots, un cop més, concedeixen una especial importància a Brossa i a la seva tasca.

Querido amigo:

Hace ya tiempo que no tengo noticias tuyas. Insisto hoy, sin embargo, para solicitar de ti 6 u 8 poemas visuales de categoría, es decir, como los que tú haces (el de la A de Hospitalet podría figurar muy bien entre ellos) [...]. Estuvieron aquí Millán y Castillejo dando una lectura. Fue un éxito. En uno de los escaparates que organizamos con este motivo quedó tu libro (el único que poseo) muy bien colocado.

És curiós de veure, en una fotografia que Boso envia a Brossa el llibre Quadern de poemes exposat en l'aparador d'una llibreria alemanya en aquells anys. Aquest llibre (junt amb Poemes per a una oda del 1970 i Poemes visuals del 1975) es convertí, dins de la seva senzillesa, en el millor passaport de la poesia visual del poeta català. 


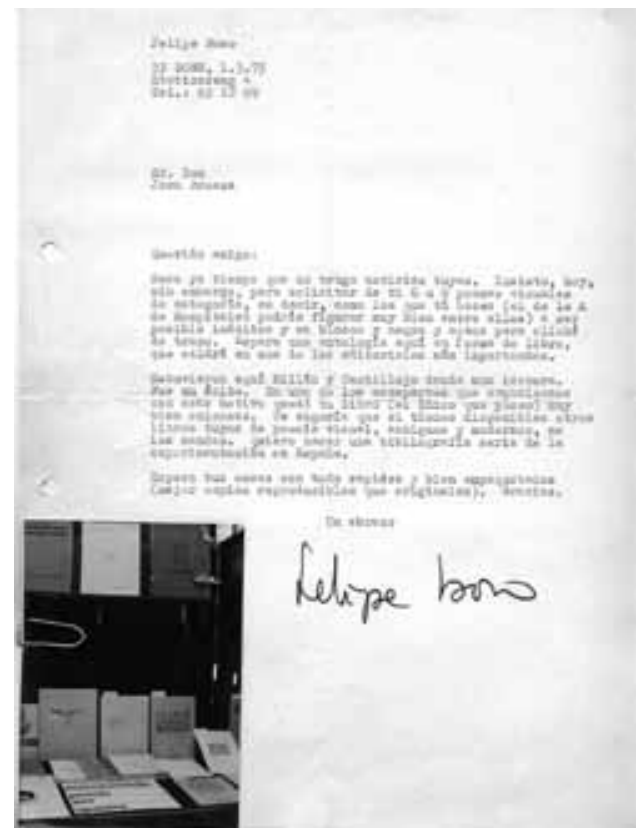

FIGURA 9 Carta de Felipe Boso a Joan Brossa (1.3.73)

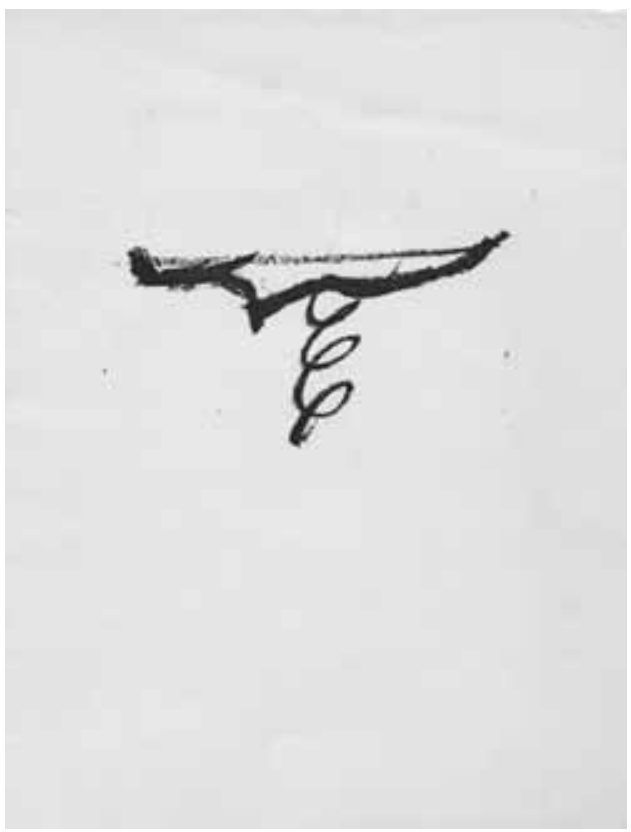

FIGURA 10 Portada (feta per Antoni Tàpies) per a Quadern de poemes de Joan Brossa (1969)

\section{CONCLUSIONS}

Aquestes cartes que aquí hem comentat mostren les complicitats d'aquells moments dins de la poesia experimental. D'altra banda, pel to amb què estan escrites, pel sentit de l'humor que les embolcalla i per les referències personals, històriques i literàries que les acompanyen, tenen el poder de transportar el lector cap al temps en què s'escriviren. Retenen la frescor d'aquella època i la seva lectura ens fa reviure converses i esdeveniments del passat que, d'aquesta manera, ens sembla tenir més a prop nostre.

Els documents seleccionats fan palesa la influència artística i intel-lectual del poeta català sobre gran nombre de poetes i artistes de diferents generacions, tot i que el seu reconeixement no arribà fins als anys 80 i 90. Als corresponsals que aquí hem destacat com a representatius de diferents especialitats o tarannàs, n’hi podríem afegir molts d'altres com Lasse Söderberg, Edgardo Antonio Vigo, Fernando Aguiar, Jean-François Bory, etc. Les seves cartes demostren que Joan Brossa fou un poeta i artista d'esperit lliure i provocador que desafià el món artístic català des de la dècada de 1940 fins a la seva mort a finals del segle xx. Fou vist pels artistes joves com un digne hereu de Salvat-Papasseit i se'l respectava com si hagués estat James Joyce, Harry Houdini o Marcel Duchamp. 
Creà obres sorprenents en una diversitat de mitjans (poesia visual, objectes, espectacles, guions de cinema, etc.), influït als seus començaments pel futurisme, el dadaisme i el surrealisme, però després desenvolupà el seu treball de manera paral-lela al Pop Art, al Teatre de l'absurd, a Fluxus, etc. de manera que tingué un gran impacte no només en els nous poetes visuals catalans dels anys setanta, sinó també en grups de teatre com La Fura dels Baus (Caulfield 20).

La seva correspondència internacional mostra el que es podria concebre com a xarxa internacional de Joan Brossa, la qual, pretesament o no, donà suport a la seva vida creativa i al seu coneixement més enllà de les fronteres catalanes. I aquí és on podríem parlar d'una autèntica "constel-lació" Brossa. Són molts els noms i seria impossible anomenar-los tots. Tanmateix, es poden perfilar grups i generacions de la mateixa manera que es pot dir que tots ells tenen una cosa en comú: la d'una creació agosarada en contra del corrent, la de l'experimentació i la de la resposta a situacions socials i polítiques repressives. En conjunt, formen un teixit divers, que ens ajuda a entendre millor no solament el personatge sinó també la seva producció i el lloc que ocupa en la història de l'art d'avantguarda internacional del segle xx. Les cartes aporten elements nous al context de l'univers del poeta, perquè hi descobrim noves fonts per a l'estudi de la seva obra i també de la dels seus corresponsals. D'altra banda, ens permeten escoltar no només les veus dels que les escrigueren, sinó també la veu del poeta català.

GLÒRIA BORDONS

Universitat de Barcelona

CARLOTA CAULFIELD

Mills College

\section{NOTES}

1 Aquest estudi s'emmarca en el projecte d'I+D "La poesia experimental catalana (1959-2004): característiques, relacions internacionals i genèriques, recepció entre els més joves". Referència FFI2013-41063-P del Programa Estatal de Fomento de la Investigación Científica y Técnica de Excelencia, Subprograma de Generación del Conocimiento (Ministerio de Economía y Competitividad). Ha rebut ajut també de l'Agrupació de Recerca en Ciències de l'Educació de la Universitat de Barcelona. En una versió preliminar es presentà com a comunicació al 15è Col-loqui Internacional de la NACS el dia 30 de juny de 2015, a l'IEC de Barcelona, sota el títol "Joan Brossa: relacions amb poetes experimentals internacionals a partir de la seva correspondència”.

2 Gràcies a la publicació del volum Poesia rasa.

3 La primera traducció a un idioma diferent de l'espanyol (n'hi ha dues de Rafael Santos Torroella el 1951) fou al suec, de la mà de Lasse Söderberg l'any 1957 (Brossa, 
“Karneval”). Publicà el poema "Karneval”, pertanyent a Romancets del Dragolí, llibre escrit el 1948 i publicat en part a la revista Dau al Set l'any 1953.

4 A més d'Arnau Puig, filòsof, i Joan Josep Tharrats, que féu possible l'edició de la revista.

5 Estigué en contacte continu amb Antoni Tàpies quan aquest anà amb una beca de l'Institut francès a París l'any 1951, com demostren les cartes intercanviades en aquell moment (Homs 151-91), i editades recentment per Núria Homs i Mònica Güell. Malgrat el seu interès per anar a França no fou fins l'any 1956 que aconseguí fer una estada a París (sobre aquesta estada a la capital francesa i altres viatges vegeu Bordons 57-74).

6 Dipositada al Centre d'Estudis i Documentació del Macba de Barcelona des de l'any 2012. Agraïm a aquest centre i al seu personal les facilitats i l'amabilitat per la consulta de les cartes objecte d'aquest estudi.

7 La correspondència de Brossa conté 2.991 cartes, entre les quals n'hi ha més de cent cinquanta de corresponsals estrangers.

8 Pepa Llopis compartí habitatge amb Brossa des de 1972. A partir d'aquell moment es convertí, en certa manera, en la "secretària" del poeta. Especialment, quan, a partir dels anys vuitanta, Brossa entrà en el món de l'art i fou més conegut en tots els àmbits, la correspondència augmentà, i, tant per edat com per disponibilitat, no tenia prou temps per poder contestar tothom. Això explica per què, després de les primeres cartes, John London, per exemple, s'adreça cada vegada més a Pepa.

9 Aquesta exposició, a la Sala Caralt, fou l'any 1951 i s'hi exhibiren tres dels primers poemes experimentals de Brossa.

10 Donem entre parèntesis els números de referència que cada carta té dins del Fons Joan Brossa, dipositat per la Fundació Joan Brossa a l'arxiu del Centre d'Estudis i Documentació del Macba.

11 Transcrivim segons la traducció del portuguès al català que aparegué a Guerrero 116.

12 Les fotografies incloses en aquest treball pertanyen al Fons Joan Brossa i la seva reproducció ha estat autoritzada per la Fundació Joan Brossa. També hem rebut autorització per a la reproducció del cartell i el poema visual de Joan Brossa, el copyright dels quals pertany a la Fundació. Agraïm la gentilesa al seu personal.

13 En francès “Tu joues” té un caràcter lúdic i teatral que en la traducció es perd.

14 Es tracta d'un esborrany de carta en francès amb una lletra que no sembla de Brossa (podria ser que se l'hagués fet escriure, perquè ell tenia un coneixement limitat en l'escriptura d'aquesta llengua). En un altre esborrany (A.JBR.02332.001) interpreta per a Jacques Dupin el significat de la primera estrofa de la composició per facilitar-ne la traducció al francès.

15 Aquest fragment està separat de la resta del text i situat més avall com si es tractés d'una postdata.

16 El poema en qüestió és "De nits", pertanyent al poemari Cau de poemes de 1960 (Brossa, Poemes de seny $i$ cabell 321).

17 Text publicat originalment a La Vanguardia, 17 d'abril de 1993 i citat a Adrian Searle, "El prestidigitador de Catalunya", The Guardian, dilluns 11 gener de 1999, la qual cosa demostra la importància de les declaracions.

18 En total, hi ha setze cartes de Julie Lawson.

19 Arthur Terry fou traductor de la poesia de Joan Brossa (és el traductor dels poemes 
inclosos al petit catàleg de l'exposició del Riverside Studios). Conegué l'obra de Brossa a primers dels setanta, s'hi entusiasmà i escriví el pròleg de (Brossa) Poemes de seny i cabell. Entre la correspondència de Brossa, hi hem trobat una carta del 1974 (A.JBR.03313), on manifesta que està llegint els seus poemes "amb plaer i profit" per fer-ne el pròleg. Entre altres coses diu: "Sovint recordo aquell sopar tan agradable a casa vostra, amb jocs de mans i música de Schumann”, la qual cosa demostra l'amistat i estimació que li tenia (i que després seguiria tenint amb Pepa).

20 Nom artístic de Jesús Julve (1953), prestidigitador a qui Brossa donà suport des dels seus inicis. L'any 1981 escriví per a ell l'Espectacle Hausson Brossa. Gran sessió de màgia en dues parts i el 1996 Poemància (Brossa, Poesia escènica VI 189-97). Ens consta a través del mateix Hausson que realitzà una petita actuació a la inauguració de Riverside Studios.

21 Artista britànic visual (1951), que també mantingué correspondència amb Brossa.

22 Traducció dels fragments de les cartes de l'anglès al català per part de les autores de l'article.

23 Julien Blaine (1942) ha practicat la poesia acció i la poesia sonora des dels anys setanta. El 1976 creà a França la revista $\operatorname{Doc}(k) s$, dedicada a la poesia experimental en tots els seus vessants. El número 12/13/14 de desembre del 1977 és dedicat a "Yougoslavie et catalans".

24 Sarenco fou un dels membres del moviment "Poesia Visiva" i editor de gran prestigi, fundador de les revisions Lotta Poetica i Poesia visiva. L'any 1997 traduí i edità dos llibres de Brossa: Poemi civili i Via Fregoli (1997), a més de produir el portfolio Tot Brossa, també a càrrec de l'editor Adriano Parise.

25 Poeta visual alemany i una figura pionera en el camp de la poesia experimental des dels anys 70, Dencker és també un teòric important de la poesia visual internacional (o poesia òptica, com ell l'anomena), des del seu ja clàssic Textbilder de 1972 fins al més recent Optische Poesie de 2011.

26 Brossa passà per diferents galeristes. La Galeria Prats, la Carles Taché i la Miguel Marcos s'encarregaren successivament de la seva obra.

27 Professor gal·lès, expert en teatre contemporani català, que edità El sarau de Joan Brossa (2000), junt a John London i que ha estudiat especialment la presència de la commedia dell'arte en el teatre de Brossa.

28 Segurament es refereix a la traductora Ursula Aszyk, que l'any 1983 ja traduïa fragments de teatre irregular i un striptease a la revista de Varsòvia Dialog 314/7.

29 Organitzat per Pep Pérez Montaner i patrocinat per l'ajuntament de l'Alfàs del Pi el 2, 3 i 4 de maig de 1996 comptà amb la participació de Julien Blaine, Til Stegmann, Dominic Keown, Giovanni Fontana, Paolo Albani i John London, entre els estrangers, a més d'una bona colla d'artistes i teòrics procedents de diferents punts dels Països Catalans, com ara Bufons, Pep Bou, Hausson, Núria Candela, Bartomeu Ferrando, entre els que tingueren una intervenció més artística.

30 Tot i que ja havia escrit accions espectacle des del 1946 o ballets des del 1948.

31 La carta està pendent de catalogació a l'arxiu del Macba, ja que no figurava entre la correspondència, sinó que es trobà en una capsa amb documents teatrals. El mateix passa amb les de Spatola i Boso que comentem en aquest mateix apartat. Per aquest motiu no tenen número de referència. 
32 Transcrivim els fragments de la carta tal com estan escrits, amb errors ortogràfics, conjugacions verbals molt "particulars", etc.

33 Concretament, publicà Ten Accio-Spectacles, en anglès, a Chicago Review l'any 1966 i Pim-pam-pum ou la pyramide de pommes, Action Spectacle, Farce, Le calendrier i Hommage au Vietcong, en francès, a la revista L'VII de Bruxelles l'any 1968.

34 Indubtablement s'està referint al llibre Frègoli, amb litografies d'Antoni Tàpies, el qual comprèn una selecció dels dos libres sobre Fregoli, escrits el 1965: Poema sobre Frègoli i el seu teatre, i Petit Festival.

35 I continua meravellant-lo ja que a data d'avui continua parlant de Brossa i vol retre-li un homenatge (amb un dels seus Public Poems) dins de l'exposició antològica que el Macba dedicarà al poeta català el 2017.

36 Les cartes són actualment en procés de transcripció.

37 Transcrivim fragments de la carta en traducció al català. Respectem l'ús de noms i inicis d'oració en minúscules.

38 Tot i això, Brossa ja havia publicat poemes tant literaris com visuals al número 52/B de la revista el setembre de 1987, en vida de Spatola.

39 Per aquest motiu, Boso dóna els tres títols en francès, tal i com apareixen a Quadern de poemes.

\section{REFERÈNCIES}

Bordons, Glòria. "Joan Brossa, una mirada cap a Europa”. Per vells carrers de poble. Territori, marca, educació i patrimoni. Ed. Jordi Chumillas i Ricard Giramé. Vic: Servei de Publicacions Institucionals UVic-UCC, 2014. 57-74.

Brossa, Joan. Sonets de Caruixa. Barcelona: Ed. Cobalto, 1949.

-. Em va fer Joan Brossa. Barcelona: Ed. Cobalto, 1951.

—. "Karneval”. Traducció de Lasse Söderberg. Upptakt 3. (1957 (Estocolm).

—. "Pim-pam-pum ou la pyramide de pommes, Action Spectacle, Farce, Le Calendrier i Hommage au Vietcong”, L'VII 33 (1968).

-. Poemes civils. Aiguafort de Joan Miró. Coberta d'Antoni Tàpies. Barcelona: Ed. R. M., 1961.

—. Poemes de seny i cabell. Pròleg d'Arthur Terry. Esplugues de Llobregat: Ariel, 1977.

- Poemes objecte. Pròleg de Sir Roland Penrose. Barcelona: Servicios Editoriales S.A., 1978.

-. Poemi civili. Traducció de Sarenco. Colognola ai Colli: Adriano Parise, 1997.

- Poesia escènica VI: circ, màgia i titelles. Ed. Glòria Bordons. Pròleg de Jordi Jané. Tarragona: Arola, 2013.

—. Poesia rasa. Pròleg de Manuel Sacristán. Esplugues de Llobregat: Ariel, 1970.—. Prosa completa i textos esparsos. Ed. Glòria Bordons. Barcelona: RBA, 2013.

-. Quadern de poemes. Barcelona: Ariel, 1969.

-. "Ten Accio-Spectacles”. Traducció d'Alain Arias-Misson. Chicago Review 18.3-4 (1966): 78-82.

- Via Fregoli: Poema su Fregoli e il suo teatro 1965; Piccolo Festival 1965. Traducció de Sarenco. Colognola ai Colli: Adriano Parise, 1997.

Brossa, Joan, i Joan Miró. Oda a Joan Miró. Barcelona: La Polígrafa, 1973. 
Brossa, Joan, i Antoni Tàpies. Frègoli. Barcelona: Sala Gaspar, 1969.

- , i - Poems from the Catalan (introducció d'Arthur Terry, pròleg de Sir Roland Penrose), en català i en anglès (traducció d'Arthur Therry). 2 vols. Londres i Barcelona: Guinness Button Publishing i Ed. La Polígrafa, 1973.

Caulfield, Carlota. "Breaking boundaries. A journey through the Catalan avant-garde". Barcelona. Visual Culture, Space and Power. Ed. Helena Buffery \& Carlota Caulfield. Cardiff, UK: University of Wales Press, 2012. 11-30.

Dencker, Klaus Peter. Optische Poesie. Von den praehistorischen Schriftzeichen bis zu den digitalen Experimenten der Gegenwart. Berlin i Nova York: Walter de Gruyter, 2011.

—.Textbilder - Visuelle Poesie International. Colönia: DuMont Verlag, 1972.

Guerrero, Manuel, ed. Joan Brossa o la revolta poètica. Barcelona: Fundació Joan Brossa, Departament de Cultura de la Generalitat de Catalunya i Fundació Joan Miró, 2001.

Homs, Núria. Annexos a “Tàpies a París. Oeuvres de 1950-1951”. Tàpies \& Paris. Ed. Jacques Terrasa. París: Éditions Hispaniques, 2014. 133-91.

London, John. Contextos de Joan Brossa. L'acció, la imatge i la paraula. Barcelona: Publicacions i edicions de la Universitat de Barcelona, 2010.

Permanyer, Lluís. Brossa $\times$ Brossa. Records. Barcelona: La Campana, 1999. 